\title{
Current medical treatment of uterine fibroids
}

\author{
Geum Seon Sohn ${ }^{1,2}$, SiHyun Cho ${ }^{1,2}$, Yong Man Kim³, Chi-Heum Cho ${ }^{4}$, Mee-Ran Kim ${ }^{5}$, Sa Ra Lee', \\ for the Working Group of Society of Uterine Leiomyoma
}

\begin{abstract}
'Department of Obstetrics and Gynecology, Gangnam Severance Hospital, Yonsei University College of Medicine, 'Institute of Women's Life Medical Science, Yonsei University College of Medicine, Seoul, Department of Obstetrics and Gynecology, ${ }^{3}$ University of Ulsan College of Medicine, Asan Medical Center, Seoul, ${ }^{4}$ Keimyung University School of Medicine, Daegu, ${ }^{5}$ Seoul St. Mary's Hospital, College of Medicine, The Catholic University of Korea, ${ }^{6}$ Ewha Womans University College of Medicine, Seoul, Korea
\end{abstract}

Uterine fibroids (leiomyomas or myomas), benign monoclonal tumors, are the most common benign tumors in women. Heavy or prolonged menstrual bleeding, abnormal uterine bleeding, resultant anemia, pelvic pain, infertility, and/or recurrent pregnancy loss are generally associated with uterine fibroids. Although curative treatment of this tumor relies on surgical therapies, medical treatments are considered the first-line treatment to preserve fertility and avoid or delay surgery. The aim of this review is to provide available and emerging medical treatment options for symptomatic uterine fibroids. Literature review and consensus of expert opinion. Many uterine fibroids are asymptomatic and require no intervention, although it is advisable to follow-up patients to document stability in size and growth. Fibroid-associated symptoms include heavy menstrual bleeding and pain or pelvic discomfort. The association between infertility and fibroids increases with age. Treatment options for symptomatic uterine fibroids - include medical, surgical, and radiologically guided interventions. Various medical therapies are now available for women with uterine fibroids, although each therapy has its own advantages and disadvantages. Currently, gonadotrophin-releasing hormone $(\mathrm{GnRH})$ agonists and selective progesterone receptor modulators (SPRMs) are the most effective medical therapies, with the most evidence to support their reduction of fibroid volume and symptomatic improvement in menstrual bleeding. The choice of treatment depends on the patient's personal treatment goals, as well as efficacy and need for repeated interventions.

Keywords: Uterine fibroids; GnRH receptor

\section{Introduction}

Uterine fibroids (leiomyomas or myomas) are the most common pelvic tumors and the most common benign tumors in women $[1,2]$. It is estimated that $60 \%$ of reproductive-aged women are affected, and $80 \%$ of women develop the disease during their lifetime [3-6].

Uterine fibroids are monoclonal tumors that arise from the uterine smooth-muscle tissue $[7,8]$. The reasons fibroids develop and grow are not well understood, but many factors are recognized as growth promoters, with sex steroids, estrogen and progesterone, being the most frequently studied [911]. Increasing age up to menopause, with incidence peaking in the fourth decade, Black ethnicity, and obesity are the wellknown risk factors for fibroids [12-14]. Both reproductive and environmental factors have been described. Some of the most common reproductive factors include nulliparity, early menarche, and the use of oral contraceptives before 16 years of age. Additional environmental factors, such as diet, particularly vitamin $D$ deficiency, and environmental toxins, are the subject of ongoing investigations $[15,16]$. Some dietary factors, including increased consumption of fruits, vegetables, and low-fat dairy products, are associated with a reduced risk.

The majority of women with uterine fibroids either remain

Received: 2017.03.23. Revised: 2017.08.22. Accepted: 2017.09.04. Corresponding author: SiHyun Cho

Department of Obstetrics and Gynecology, Gangnam Severance Hospital, Yonsei University College of Medicine, 211 Eonju-ro,

Gangnam-gu, Seoul 06273, Korea

E-mail: sihyuncho@yuhs.ac

https://orcid.org/0000-0003-2718-6645

Articles published in Obstet Gynecol Sci are open-access, distributed under the terms of the Creative Commons Attribution Non-Commercial License (http://creativecommons. org/licenses/by-nc/3.0/) which permits unrestricted non-commercial use, distribution, and reproduction in any medium, provided the original work is properly cited.

Copyright $\odot 2018$ Korean Society of Obstetrics and Gynecology 


\section{Obstetrics \& Gynecology Science}

Geum Seon Sohn, et al. Current medical treatment of uterine fibroids

asymptomatic or develop symptoms gradually over time. When patients are symptomatic, the number, size, and/ or location of fibroids are critical determinants of its clinical manifestations. Commonly reported symptoms include heavy menstrual bleeding, dysmenorrhea, noncyclic pain, urinary symptoms, fatigue, and constipation $[5,17]$. The association between infertility and fibroids is limited. A recent metaanalysis demonstrated that submucosal, intramural, and subserosal fibroids have different effects on fertility, and they are mostly related to submucosal lesions resulting in implantation defects [18-20].

Hysterectomy was considered the only curative solution for fibroids; however, alternate medical treatments that preserve fertility and avoid invasive surgery, with high efficacy, and a desirable side effect profile are now available. We reviewed the use of well-known medical treatments, both as adjuvant therapy and as primary therapy. The discussion focuses on gonadotrophin-releasing hormone $(\mathrm{GnRH})$ analogues, the levonorgestrel-releasing intrauterine system (LNG-IUS), selective progesterone receptor modulators (SPRMs), and aromatase inhibitors (Als). Each carries its own safety and effectiveness profile, and the treatment of fibroids must be individualized depending on such factors as the patient's age, signs and symptoms, sustained reduction of fibroid size, and maintenance or improvement of fertility, while minimizing side effects.

\section{Combination oral contraceptives}

Observational data support the use of oral contraceptives to reduce menstrual bleeding in women with fibroids [21]. As uterine fibroid growth is stimulated by both estrogens and progestins, Combination oral contraceptives (COCs) were considered a risk factor for fibroid growth, in the past. However, a recent meta-analysis suggests that uterine fibroids should not be considered a contraindication for COC use [22]. In the short-term, COCs can be used to improve heavy menstrual bleeding associated with fibroids, primarily through their suppressive effects on endometrial proliferation, but overall they have no effect on decreasing uterine fibroid volume or uterine size $[21,22]$. Some studies suggest that COCs are not recommended for myoma-related symptoms [23], whereas some use COCs, but close monitoring of uterine myoma and uterine size is recommended [24]. A randomized controlled trial comparing COCs with a LNG-IUS for the treatment of fibroids showed the superiority of the LNG-IUS, but the COC still demonstrated a reduction in menstrual blood loss and no significant change in the volume of the tumors [25]. Although there is a lack of robust evidence regarding the efficacy of these medications, trials with COCs may still be effective in some women with uterine fibroids due to their advantages of easy accessibility, oral administration, and low cost [26].

\section{Progestins}

The cyclic use of progestins for bleeding control has been used in cases of non-organic abnormal uterine bleeding, such as perimenopausal bleeding and endometrial hyperplasia-related bleeding. Although often administered in the treatment of uterine fibroids, as with previous COCs, there is some opinion that progestin does not recommend treating symptoms associated with uterine fibroids [23]. There is a lack of highquality evidence assessing the efficacy of these medications, and they may even promote uterine fibroid cell growth. In one study, depot medroxyprogesterone acetate (DMPA) was used in 20 women with uterine fibroid-induced bleedings [27]. After 6 months, 30\% were amenorrheic, 70\% had an improved bleeding pattern, and $15 \%$ had an increase in hematocrit. Uterine and fibroid volumes were decreased by $48 \%$ and $33 \%$, respectively. Two other studies assessing the efficacy of oral progestogens in women with fibroids were conducted. One of them compared lynestrenol, an oral progestogen, with leuprolide, a GnRH agonist, and demonstrated no significant difference between the treatments in improving pelvic pain and uterine bleeding. The other study, which included only 18 patients, compared dienogest, an oral progestogen, with leuprolide, demonstrating a significant decrease in tumor volume with both treatments (50\% and $60 \%$, respectively) [28]. Treating uterine fibroids with progestogens may be effective in some cases, but such treatment has been associated with histopathological changes that may be mistaken for leiomyosarcoma or smooth-muscle tumors of unknown malignant potential, such as an increase in cellularity and mitotic activity.

\section{LNG-IUS}

In 2009, the Food and Drug Administration (FDA) approved the LNG-IUS to treat heavy menstrual bleeding in women 


\section{Obstetrics \& Gynecology Science}

Vol. 61, No. 2, 2018

who opt for an intrauterine device for contraception. As it was well-known as an effective treatment for non-organic abnormal uterine bleeding, its use for treating uterine fibroidrelated bleeding, was soon investigated. A randomized controlled trial comparing LNG-IUS with a low-dose COC in women with fibroids, demonstrated that the former was more effective in reducing uterine fibroid-related bleeding than the latter, although the trial suffered from high attrition rates and assessed uterine bleeding in only 22 patients $[25,29]$. In the LNG-IUS group, there was a significant decrease in menstrual blood loss and uterine volume, while hematocrit increased. In a systematic review by Zapata and colleagues [30], they reported that menstrual blood loss decreased in the 11 studies included in their analysis. These investigations also demonstrated an increase in hemoglobin, hematocrit, and ferritin. Although numerous studies indicate improvement in menstrual bleeding and hemoglobin levels when used in women with uterine fibroids, they do not demonstrate an appreciable change in fibroid volume, as measured by magnetic resonance imaging (MRI) and other imaging modalities $[29,31,32]$.

Once inserted, the LNG-IUS is effective for up to 5 years, thus potentially providing women with a long-term treatment option. Because it is not administered systemically, minimal side effects are reported and no additional patient's compliance after insertion is required, as there is no need for daily/ monthly injections. However, given the increased risk of expulsion, it is probably an effective option in selected symptomatic women with no endometrial distortion.

\section{GnRH agonists}

Native $\mathrm{GnRH}$, a decapeptide, is produced and released in a pulsatile pattern from the hypothalamus. GnRH agonists are synthetic peptides structurally close to the natural GnRH molecule, but they are more potent and have a longer half-life than native $\mathrm{GnRH}[33,34]$. When administered, they increase follicle-stimulating hormone (FSH) and luteinizing hormone (LH) secretion initially, known as the flare effect. After that, they subsequently cause receptor down-regulation, followed 1-3 weeks later by a hypogonadotropic hypogonadal state, often termed - "pseudomenopause". This hypoestrogenic state contributes to the pharmacologic efficacy of GnRH agonists, as leiomyoma growth is stimulated by estrogen. Several studies have shown that tumor shrinkage is proportional to the number of estrogen receptor (ER)-positive cells [33,35].

$\mathrm{GnRH}$ agonists have been most extensively studied for the treatment of symptomatic uterine fibroids, especially adjuvant preoperative medical therapy. The Cochrane Systematic Review, a systematic review of 26 randomized controlled trials to determine the efficacy of GnRH agonists when before hysterectomy or myomectomy, showed notable therapeutic benefits [36,37]. A significant improvement in both pre- and postoperative hemoglobin levels and significant reductions in uterine volume, uterine gestational size, fibroid volume, and duration of hospital stay were noted. In addition, blood loss and rate of vertical incisions were also reduced for both myomectomy and hysterectomy [28]. The usage of GnRH agonists seems to be more beneficial in cases of large uterine fibroids ( $>10$ $\mathrm{cm}$ ) if the myomectomy is to be performed laparoscopically, thus reducing operative time, intraoperative bleeding, and the risk of blood transfusion. Besides, GnRH agonists may also be beneficial prior to hysteroscopic resection of submucosal myomas, and one randomized controlled trial demonstrated that the preoperative use of GnRH agonists helped decrease operative times, fluid absorption, and the difficulty of the hysteroscopic procedure.

Despite FDA approval, menopausal symptoms, such as hot flashes and atrophic vaginitis, and a decrease in bone mineral density (BMD) after long-term use limit GnRH agonists to short-term adjuvant therapy in most patients. As a result of these hypoestrogenic side effects, long-term GnRH agonist therapy necessitates the use of hormonal add-back therapy to offset some of the hypoestrogenic symptoms and preserve BMD $[38,39]$. Furthermore, GnRH agonists treatment is associated with histological changes in uterine fibroids that may complicate surgical intervention. Treatment with leuprolide acetate preoperatively can cause myoma degeneration and obliteration of the interface between the myoma and myometrium, making the enucleation of myomatous nodules and removal difficult. These myxoid changes may result in very small uterine fibroids that become too soft and difficult to visualize; thus, during myomectomy, these uterine fibroids may be missed.

\section{GnRH antagonists}

GnRH antagonists act immediately to suppress the secretion 


\section{Obstetrics \& Gynecology Science}

Geum Seon Sohn, et al. Current medical treatment of uterine fibroids

of FSH and LH by blocking pituitary GnRH receptors. The subsequent reduction in estradiol levels leads to improvement in bleeding patterns and a reduction in uterine fibroid size as early as 3 weeks after initiation of treatment $[40,41]$. Because of its rapid onset of action, and avoidance of a gonadotropin flare effect, patients experience faster symptom relief [42].

A randomized trial studied the effect of cetrorelix acetate, a GnRH antagonist for 4 weeks prior to surgical treatment in 109 women, demonstrating a significant reduction in tumor volume and uterine volume compared with placebo $[43,44]$. A smaller, open-label study including only 19 patients reported on the efficacy of ganirelix, another GnRH antagonist, in decreasing tumor volumes and uterine volumes over a median treatment duration of 19 days [45]. Further research into dosing and adverse effects is needed.

\section{SPRMs}

In vitro studies demonstrate that progesterone stimulates proliferative activity in cultured uterine fibroid cells, but not in normal myometrial cells [46]. Compared with the normal female myometrium, uterine fibroids overexpress ERs and progesterone receptors (PRs), and there is complex cross-talk between the ER and PR signaling pathways. It has been shown that uterine fibroids grow primarily during the secretory phase of the menstrual cycle $[47,48]$, and exogenous progesterone increases mitotic activity and cellularity in this tumor $[47,49]$. An in vivo model in which human fibroid tissue was grafted under the kidney capsule in mice revealed that progesterone and its receptor were essential and sufficient for tumor growth, as indicated by the stimulation of cell proliferation, the accumulation of extracellular matrix, and cellular hypertrophy. A number of clinical observations also support these findings [50]. The use of progestins in hormone-replacement regimens stimulates the growth of fibroids in postmenopausal women in a dose-dependent manner, and the addition of progestins to $\mathrm{GnRH}$ agonists diminishes the inhibitory effects of these agonists on uterine fibroid size [51]. Progesterone is therefore essential for fibroid growth, and these observations have stimulated research for the development of progesterone antagonist and/or SPRM drugs $[9,10,52]$.

SPRMs have tissue-specific effects at PRs, and they can have either a complete PR agonist or antagonist profile or a mixed agonist/antagonist profile [53]. These agents, including mife- pristone, telapristone, onapristone, asoprisnil, and ulipristal, have emerged as a promising therapy for the management of uterine fibroids, and randomized trials have been conducted. Historically, mifepristone was the first PR antagonist, and it has been in clinical use for over 25 years now [54-56]. Much of the early clinical research with selective progesterone modulators involved the use of mifepristone and asoprisnil [5658]. Both drugs have been shown to be effective in reducing uterine fibroid size and improving myoma-related symptoms. More recently, ulipristal acetate (UPA), approved for emergency contraception in the US, has been the focus of clinical investigations. UPA has been shown to improve quality of life, reduce fibroid volume, and induce amenorrhea in most of the women treated, and it is now approved for clinical use in both Europe and Canada.

Mifepristone is a synthetic 19-norsteroid SPRM with primarily PR antagonist activity, and it was one of the first SPRMs to be developed and commonly utilized. Although mifepristone is most commonly recognized as RU-486, an antiprogesterone used as an abortifacient, it also exhibits inhibitory effects on uterine fibroid growth [59]. A randomized controlled trial in 2009 assessed patients treated with mifepristone compared with placebo and noted a significant reduction in uterine size, resolution of anemia, and improvement in symptoms of menorrhagia [54]. A subsequent Cochrane review of 3 randomized controlled trials evaluating mifepristone for the treatment of symptomatic fibroids demonstrated significantly reduced bleeding and improved quality of life in users of mifepristone, but no significant reduction in fibroid volume [60]. Therefore, mifepristone was not recommended on the basis of this systematic review until better-powered randomized controlled trials were conducted [61].

UPA, CDB-2914 is a synthetic steroid derived from 19-norprogesterone $[62,63]$, which is a selective PR modulator that binds to PR-A and PR-B with high affinity [64]. The binding and antagonist potency of UPA with the glucocorticoid receptor is significantly reduced compared to mifepristone. UPA is tissue selective, with preferential binding noted in the uterus, cervix, ovaries, and hypothalamus $[46,53,65]$.

Many clinical studies have evaluated the efficacy of UPA in the treatment of symptomatic uterine fibroids; however, the most widely cited studies investigating UPA include the European phase III studies, PGL4001 Efficacy Assessment in Reduction of Symptoms Due to Uterine Leiomyomata (PEARL), which demonstrate UPA's safety and efficacy. 


\title{
Obstetrics \& Gynecology Science
}

\author{
Vol. 61, No. 2, 2018
}

PEARL I compared UPA at a dosage of 5 and $10 \mathrm{mg} /$ day with placebo for a 13-week treatment period. It effectively controlled uterine bleeding and reduced the size of fibroids, as measured by MRI compared with placebo. Rates of amenorrhea were high in women treated with UPA, occurring very early, achieved within the first 10 days after initiation of treatment [66].

PEARL II was a double-blinded, noninferiority trial that included 307 patients randomly assigned to 5 or $10 \mathrm{mg}$ of UPA vs. a GnRH agonist, depot leuprolide acetate, for 3 months of treatment [67]. UPA controlled bleeding in nearly $100 \%$ of women, and they achieved amenorrhea 2 weeks earlier than women treated with leuprolide. The major benefit of UPA over leuprolide acetate is the reduced -hypoestrogenic side effects and bone loss. These differences between UPA and leuprolide may make UPA a preferred choice for preoperative adjuvant therapy (10\% vs. $40 \%$ in the leuprolide acetate group, $P<0.001)$.

PEARL III assessed the efficacy and safety of long-term UPA treatment in women with symptomatic fibroids. Patients were treated with UPA $10 \mathrm{mg}$ daily, followed by norethindrone acetate (NETA) $10 \mathrm{mg}$ daily vs. placebo for 10 days. Thereafter, patients could either leave the study or continue UPA $10 \mathrm{mg}$ (and NETA/placebo) for up to three 12-week courses. In between each 12-week course, patients received no treatment and were required to have a full menses before receiving additional UPA treatment. The study showed that amenorrhea was obtained after a mean of 3.5 days in the first UPA treatment period, and 2-3 days in subsequent courses. About 90\% of women were amenorrheic after the first course, and $93 \%$ $94 \%$ of them had spotting or no bleeding at all in the subsequent courses. Fibroid volume reduction reached $45 \%$ after the first course and continued to decrease in subsequent treatment rounds to $72 \%$ after the fourth treatment course $[68,69]$.

PEARL IV was a Phase III multicenter, randomized, doubleblind, parallel group, long-term study investigating the efficacy and safety of 5 and $10 \mathrm{mg}$ doses of UPA during 2 treatment courses. Repeated 12-week courses of daily oral UPA (5 and $10 \mathrm{mg}$ ) effectively controlled bleeding (>80\%, in both groups) and pain, reduced fibroid volume (54\% and 58\%), and restored quality of life in patients with symptomatic fibroids. UPA was well tolerated with less than $5 \%$ of patients discontinuing treatment due to adverse events $[70,71]$.

There has been some concern regarding endometrial changes induced by medium- to long-term (3-6 months) con- tinuous daily dosing of SPRMs. Non-physiologic endometrial changes characterized by dilated weakly secretory endometrial glands with few mitotic figures, and stromal effects ranging from compaction to nonuniform edema have been described, which have been termed "progesterone receptor modulatorassociated endometrial changes (PAECs)." PAECs occur in approximately $50 \%$ of all patients. Additional data from the PEARL I, II, and III studies confirmed that PAECs were not a matter of concern. Endometrial thickening $>16 \mathrm{~mm}$ occurred in $10 \%-12 \%$ of women, and endometrial histologic samples revealed no atypia, either simple or complex, in the treated groups. PAECs are reversible 1-2 months after cessation of UPA treatment $[72,73]$.

Based on these advantages, UPA administration could render new established conservative treatment options for uterine fibroid feasible.

\section{Selective estrogen receptor modulators}

A large body of experimental data and circumstantial evidence suggests that estrogen stimulates the growth of uterine fibroids through ER- $\alpha$. The primary roles of estrogen and ER- $\alpha$ in myoma growth are permissive, in that they enable tissue to respond to progesterone by inducing the expression of PR $[74,75]$.

Selective estrogen receptor modulators (SERMs) are nonsteroidal ER ligands that display tissue-specific ER agonist and/or antagonist estrogenic actions via tissue-specific alterations in gene expression. These medications were originally used for the treatment of ER-positive breast cancer. Two of the most commonly studied SERMs in the treatment of uterine fibroids include tamoxifen and raloxifene [76-78].

Tamoxifen has an agonist action on endometrial ERs and carries the risk of leading to endometrial pathology. One small randomized, blinded controlled trial compared tamoxifen 20 mg daily vs. placebo in women with symptomatic uterine fibroids. Patients were treated for a 6-month duration, and those receiving tamoxifen showed a significant improvement in menstrual blood loss but no improvement in fibroid size or uterine volume. The study subjects reported many side effects, including hot flush, dizziness, and benign endometrial thickening. Therefore, the negative side effects outweigh the marginal benefits of tamoxifen therapy, and its use is not recommended for the treatment of symptomatic uterine fibroids.

Raloxifene, on the other hand, displays no agonist effect 


\section{Obstetrics \& Gynecology Science}

Geum Seon Sohn, et al. Current medical treatment of uterine fibroids

on the endometrium and only subtle antiestrogenic effects on mammary tissue [79]. A Cochrane review that included 3 studies and a total of 215 participants evaluated the use of raloxifene in the treatment of symptomatic uterine fibroids. Two of these trials, showed the therapeutic efficacy of raloxifene, but the third did not [76-78]. This review concluded that the effect of raloxifene on fibroid size and bleeding patterns is unclear; thus, larger controlled trials are needed before this agent can be recommended.

\section{Als}

The mechanism underlying the gonadotropin-independent expression of aromatase in uterine fibroid tissue is not completely understood. It is likely that local aromatase activity in uterine fibroid is clinically relevant, because uterine fibroid tissues from Black women - who have an increased prevalence of uterine fibroid and an earlier age at diagnosis, as compared with White women - contain high levels of aromatase, which result in elevated levels of estrogen in tissues [80].

Als, exerting their effects by blocking the extragonadal conversion of androgens into estrogens, have become standard adjuvant therapy for postmenopausal women with ERpositive breast cancer, as a result of their ability to produce in situ estrogen inhibition as compared with the indirect inhibition induced by $\mathrm{GnRH}$ agonists [80-82]. These properties also make Al very attractive candidates for the medical treatment of uterine fibroids. Als are as effective as GnRH analogues in shrinking fibroid volume, despite stable levels of circulating estrogen. These observations suggest that the inhibition of aromatase in fibroid tissue is a key mechanism in hormonedependent fibroid growth.

Two third-generation agents, letrozole ( $2.5 \mathrm{mg}$ daily) and anastrozole (1 $\mathrm{mg}$ daily), have been studied for the treatment of symptomatic uterine fibroids [81,83-85]. Several small observational studies have shown a reduction in fibroid size and improvement of symptoms with Al therapy. Only one randomized trial has compared letrozole and the GnRH agonist triptorelin for 12 weeks of treatment in premenopausal women with symptomatic uterine fibroids $[84,85]$. This Cochrane review of one eligible study concluded that the evidence was still insufficient to fully support the use of Als for women with symptomatic uterine fibroids.

\section{Conclusion}

Uterine fibroids are highly prevalent in reproductive-aged women, and as women continue to delay childbearing, an increasing number of patients will require fertility-preserving treatment options. Medical management of uterine fibroids may provide symptomatic relief of the uterine fibroid-related symptoms along with the opportunity to maintain fertility. A wide range is now available and some require further evaluation. Currently, GnRH agonists and SPRMs are the most effective medical therapies, with the most evidence to support their reduction of fibroid volume and symptomatic improvement in menstrual bleeding. The choice of treatment depends on the patient's personal treatment goals, as well as efficacy and need for repeated interventions.

\section{Conflict of Interest}

No potential conflict of interest relevant to this article was reported.

\section{References}

1. Baird DD, Dunson DB, Hill MC, Cousins D, Schectman $J M$. High cumulative incidence of uterine leiomyoma in black and white women: ultrasound evidence. Am J Obstet Gynecol 2003;188:100-7.

2. Walker $\mathrm{CL}$, Stewart EA. Uterine fibroids: the elephant in the room. Science 2005;308:1589-92.

3. Myers SL, Baird DD, Olshan AF, Herring AH, Schroeder JC, Nylander-French LA, et al. Self-report versus ultrasound measurement of uterine fibroid status. J Womens Health (Larchmt) 2012;21:285-93.

4. Ryan GL, Syrop CH, Van Voorhis BJ. Role, epidemiology, and natural history of benign uterine mass lesions. Clin Obstet Gynecol 2005;48:312-24.

5. Zimmermann A, Bernuit D, Gerlinger C, Schaefers $M$, Geppert K. Prevalence, symptoms and management of uterine fibroids: an international internet-based survey of 21,746 women. BMC Womens Health 2012;12:6.

6. Marshall LM, Spiegelman D, Barbieri RL, Goldman MB, Manson JE, Colditz GA, et al. Variation in the incidence of uterine leiomyoma among premenopausal women by 


\title{
Obstetrics \& Gynecology Science
}

\author{
Vol. 61, No. 2, 2018
}

age and race. Obstet Gynecol 1997;90:967-73.

7. Linder D, Gartler SM. Glucose-6-phosphate dehydrogenase mosaicism: utilization as a cell marker in the study of leiomyomas. Science 1965;150:67-9.

8. Holdsworth-Carson SJ, Zaitseva M, Vollenhoven BJ, Rogers PA. Clonality of smooth muscle and fibroblast cell populations isolated from human fibroid and myometrial tissues. Mol Hum Reprod 2014;20:250-9.

9. Tamaya T, Nioka S, Furuta N, Shimura T, Boku S, Okada H. Progesterone receptor in human endometrium of leiomyoma uteri. Endocrinol Jpn 1977;24:523-8.

10. Maruo T. Progesterone and progesterone receptor modulator in uterine leiomyoma growth. Gynecol Endocrinol 2007;23:186-7.

11. Ishikawa H, Ishi K, Serna VA, Kakazu R, Bulun SE, Kurita T. Progesterone is essential for maintenance and growth of uterine leiomyoma. Endocrinology 2010;151:2433-42.

12. Peddada SD, Laughlin SK, Miner K, Guyon JP, Haneke K, Vahdat $\mathrm{HL}$, et al. Growth of uterine leiomyomata among premenopausal black and white women. Proc Natl Acad Sci U S A 2008;105:19887-92.

13. Radin RG, Rosenberg L, Palmer JR, Cozier YC, Kumanyika SK, Wise LA. Hypertension and risk of uterine leiomyomata in US black women. Hum Reprod 2012;27:1504-9.

14. Wise LA, Radin RG, Palmer JR, Rosenberg L. Association of intrauterine and early life factors with uterine leiomyomata in black women. Ann Epidemiol 2012;22:84754.

15. Baird DD, Hill MC, Schectman JM, Hollis BW. Vitamin $d$ and the risk of uterine fibroids. Epidemiology 2013;24:447-53.

16. Paffoni A, Somigliana E, Vigan P, Benaglia L, Cardellicchio L, Pagliardini L, et al. Vitamin D status in women with uterine leiomyomas. J Clin Endocrinol Metab 2013;98:E1374-8.

17. Gupta S, Jose J, Manyonda I. Clinical presentation of fibroids. Best Pract Res Clin Obstet Gynaecol 2008;22:615-26.

18. Jayakrishnan K, Menon V, Nambiar D. Submucous fibroids and infertility: effect of hysteroscopic myomectomy and factors influencing outcome. J Hum Reprod Sci 2013;6:35-9.

19. Pritts EA, Parker WH, Olive DL. Fibroids and infertility: an updated systematic review of the evidence. Fertil Steril
2009;91:1215-23.

20. Zepiridis LI, Grimbizis GF, Tarlatzis BC. Infertility and uterine fibroids. Best Pract Res Clin Obstet Gynaecol 2016;34:66-73.

21. Marret $H$, Fritel $X$, Ouldamer $L$, Bendifallah $S$, Brun JL, De Jesus I, et al. Therapeutic management of uterine fibroid tumors: updated French guidelines. Eur J Obstet Gynecol Reprod Biol 2012;165:156-64.

22. Qin J, Yang T, Kong F, Zhou Q. Oral contraceptive use and uterine leiomyoma risk: a meta-analysis based on cohort and case-control studies. Arch Gynecol Obstet 2013;288:139-48.

23. Hoffman BL, Williams JW. Williams gynecology. 2nd ed. New York (NY): McGraw-Hill Medical; 2012.

24. American College of Obstetricians and Gynecologists. ACOG committee opinion no. 557: management of acute abnormal uterine bleeding in nonpregnant reproductive-aged women. Obstet Gynecol 2013;121:891-6.

25. Sayed GH, Zakherah MS, El-Nashar SA, Shaaban MM. A randomized clinical trial of a levonorgestrel-releasing intrauterine system and a low-dose combined oral contraceptive for fibroid-related menorrhagia. Int J Gynaecol Obstet 2011;112:126-30.

26. American College of Obstetricians and Gynecologists. ACOG practice bulletin. Alternatives to hysterectomy in the management of leiomyomas. Obstet Gynecol 2008;112:387-400.

27. Venkatachalam S, Bagratee JS, Moodley J. Medical management of uterine fibroids with medroxyprogesterone acetate (Depo Provera): a pilot study. J Obstet Gynaecol 2004;24:798-800.

28. Ichigo S, Takagi H, Matsunami K, Suzuki N, Imai A. Beneficial effects of dienogest on uterine myoma volume: a retrospective controlled study comparing with gonadotropin-releasing hormone agonist. Arch Gynecol Obstet 2011;284:667-70.

29. Socolov D, Blidaru I, Tamba B, Miron N, Boiculese L, Socolov R. Levonorgestrel releasing-intrauterine system for the treatment of menorrhagia and/or frequent irregular uterine bleeding associated with uterine leiomyoma. Eur J Contracept Reprod Health Care 2011;16:480-7.

30. Zapata LB, Whiteman MK, Tepper NK, Jamieson DJ, Marchbanks PA, Curtis KM. Intrauterine device use among women with uterine fibroids: a systematic review. Contraception 2010;82:41-55. 


\section{Obstetrics \& Gynecology Science}

Geum Seon Sohn, et al. Current medical treatment of uterine fibroids

31. Jiang W, Shen Q, Chen M, Wang Y, Zhou Q, Zhu X, et al. Levonorgestrel-releasing intrauterine system use in premenopausal women with symptomatic uterine leiomyoma: a systematic review. Steroids 2014;86:69-78.

32. Kriplani A, Awasthi D, Kulshrestha V, Agarwal N. Efficacy of the levonorgestrel-releasing intrauterine system in uterine leiomyoma. Int J Gynaecol Obstet 2012;116:35-8.

33. Islam MS, Protic O, Giannubilo SR, Toti P, Tranquilli AL, Petraglia $F_{\text {, et }}$ al. Uterine leiomyoma: available medical treatments and new possible therapeutic options. J Clin Endocrinol Metab 2013;98:921-34.

34. De Leo V, Morgante G, La Marca A, Musacchio MC, Sorace $M$, Cavicchioli $C$, et al. A benefit-risk assessment of medical treatment for uterine leiomyomas. Drug Saf 2002;25:759-79.

35. Singh SS, Belland L. Contemporary management of uterine fibroids: focus on emerging medical treatments. Curr Med Res Opin 2015;31:1-12.

36. Lethaby A, Vollenhoven B, Sowter M. Pre-operative GnRH analogue therapy before hysterectomy or myomectomy for uterine fibroids. Cochrane Database Syst Rev 2000:CD000547.

37. Lethaby A, Vollenhoven B, Sowter M. Pre-operative $\mathrm{GnRH}$ analogue therapy before hysterectomy or myomectomy for uterine fibroids. Cochrane Database Syst Rev 2001:CD000547.

38. Palomba S, Affinito P, Di Carlo C, Bifulco G, Nappi C. Long-term administration of tibolone plus gonadotropinreleasing hormone agonist for the treatment of uterine leiomyomas: effectiveness and effects on vasomotor symptoms, bone mass, and lipid profiles. Fertil Steril 1999;72:889-95.

39. Palomba S, Orio F Jr, Morelli M, Russo T, Pellicano M, Nappi $C$, et al. Raloxifene administration in women treated with gonadotropin-releasing hormone agonist for uterine leiomyomas: effects on bone metabolism. J Clin Endocrinol Metab 2002;87:4476-81.

40. Sabry M, Al-Hendy A. Innovative oral treatments of uterine leiomyoma. Obstet Gynecol Int 2012;2012:943635.

41. Reissmann T, Diedrich K, Comaru-Schally AM, Schally AV. Introduction of LHRH-antagonists into the treatment of gynaecological disorders. Hum Reprod 1994;9:769.

42. Kettel LM, Murphy AA, Morales AJ, Rivier J, Vale W, Yen SS. Rapid regression of uterine leiomyomas in response to daily administration of gonadotropin-releasing hor- mone antagonist. Fertil Steril 1993;60:642-6.

43. Gonzalez-Barcena D, Alvarez RB, Ochoa EP, Cornejo IC, Comaru-Schally AM, Schally AV, et al. Treatment of uterine leiomyomas with luteinizing hormone-releasing hormone antagonist Cetrorelix. Hum Reprod 1997;12:202835.

44. Britten JL, Malik M, Levy G, Mendoza M, Catherino WH. Gonadotropin-releasing hormone $(\mathrm{GnRH})$ agonist leuprolide acetate and GnRH antagonist cetrorelix acetate directly inhibit leiomyoma extracellular matrix production. Fertil Steril 2012;98:1299-307.

45. Flierman PA, Oberyé JJ, van der Hulst VP, de Blok S. Rapid reduction of leiomyoma volume during treatment with the GnRH antagonist ganirelix. BJOG 2005; 112:638-42.

46. Maruo T, Ohara N, Matsuo H, Xu Q, Chen W, SitrukWare $R$, et al. Effects of levonorgestrel-releasing IUS and progesterone receptor modulator PRM CDB-2914 on uterine leiomyomas. Contraception 2007;75:599-103.

47. Kawaguchi K, Fujii S, Konishi I, Nanbu Y, Nonogaki H, Mori T. Mitotic activity in uterine leiomyomas during the menstrual cycle. Am J Obstet Gynecol 1989;160:63741.

48. Kawaguchi K, Fujii S, Konishi I, Iwai T, Nanbu Y, Nonogaki $\mathrm{H}$, et al. Immunohistochemical analysis of oestrogen receptors, progesterone receptors and $\mathrm{Ki}-67$ in leiomyoma and myometrium during the menstrual cycle and pregnancy. Virchows Arch A Pathol Anat Histopathol 1991;419:309-15.

49. Segaloff A, Weed JC, Sternberg WH, Parson W. The progesterone therapy of human uterine leiomyomas. J Clin Endocrinol Metab 1949;9:1273-91.

50. Tsigkou A, Reis FM, Lee MH, Jiang B, Tosti C, Centini G, et al. Increased progesterone receptor expression in uterine leiomyoma: correlation with age, number of leiomyomas, and clinical symptoms. Fertil Steril 2015;104:170175.e1.

51. Friedman AJ, Daly M, Juneau-Norcross M, Gleason R, Rein MS, LeBoff M. Long-term medical therapy for leiomyomata uteri: a prospective, randomized study of leuprolide acetate depot plus either oestrogen-progestin or progestin 'add-back' for 2 years. Hum Reprod 1994;9:1618-25.

52. Kim JJ, Sefton EC. The role of progesterone signaling in the pathogenesis of uterine leiomyoma. Mol Cell Endo- 


\title{
Obstetrics \& Gynecology Science
}

\author{
Vol. 61, No. 2, 2018
}

crinol 2012;358:223-31.

53. Chwalisz K, Perez MC, Demanno D, Winkel C, Schubert G, Elger W. Selective progesterone receptor modulator development and use in the treatment of leiomyomata and endometriosis. Endocr Rev 2005;26:423-38.

54. Feng C, Meldrum S, Fiscella K. Improved quality of life is partly explained by fewer symptoms after treatment of fibroids with mifepristone. Int I Gynaecol Obstet 2010;109:121-4.

55. Kulshrestha V, Kriplani A, Agarwal N, Sareen N, Garg $\mathrm{P}$, Hari $\mathrm{S}$, et al. Low dose mifepristone in medical management of uterine leiomyoma - an experience from a tertiary care hospital from north India. Indian J Med Res 2013;137:1154-62.

56. Shen Q, Hua $Y$, Jiang $W$, Zhang W, Chen M, Zhu X. Effects of mifepristone on uterine leiomyoma in premenopausal women: a meta-analysis. Fertil Steril 2013;100:1722-1726.e1-10.

57. Murphy AA, Kettel LM, Morales AJ, Roberts VJ, Yen SS. Regression of uterine leiomyomata in response to the antiprogesterone RU 486. J Clin Endocrinol Metab 1993;76:513-7.

58. Reinsch RC, Murphy AA, Morales AJ, Yen SS. The effects of RU 486 and leuprolide acetate on uterine artery blood flow in the fibroid uterus: a prospective, randomized study. Am J Obstet Gynecol 1994;170:1623-7.

59. Eisinger SH, Bonfiglio T, Fiscella K, Meldrum S, Guzick DS. Twelve-month safety and efficacy of low-dose mifepristone for uterine myomas. J Minim Invasive Gynecol 2005;12:227-33.

60. Tristan M, Orozco LJ, Steed A, Ramírez-Morera A, Stone P. Mifepristone for uterine fibroids. Cochrane Database Syst Rev 2012:CD007687.

61. Carbonell JL, Acosta R, Pérez Y, Marrero AG, Trellez E, Sánchez $C$, et al. Safety and effectiveness of different dosage of mifepristone for the treatment of uterine fibroids: a double-blind randomized clinical trial. Int J Womens Health 2013;5:115-24.

62. Biglia N, Carinelli S, Maiorana A, D'Alonzo M, Lo Monte G, Marci R. Ulipristal acetate: a novel pharmacological approach for the treatment of uterine fibroids. Drug Des Devel Ther 2014;8:285-92.

63. Courtoy GE, Donnez J, Marbaix E, Dolmans MM. In vivo mechanisms of uterine myoma volume reduction with ulipristal acetate treatment. Fertil Steril 2015;104:426- 434.e1.

64. Nieman LK, Blocker W, Nansel T, Mahoney S, Reynolds J, Blithe D, et al. Efficacy and tolerability of CDB-2914 treatment for symptomatic uterine fibroids: a randomized, double-blind, placebo-controlled, phase Ilb study. Fertil Steril 2011;95:767-772.e1-2.

65. Luyckx M, Squifflet JL, Jadoul P, Votino R, Dolmans MM, Donnez J. First series of 18 pregnancies after ulipristal acetate treatment for uterine fibroids. Fertil Steril 2014;102:1404-9.

66. Donnez J, Tatarchuk TF, Bouchard P, Puscasiu L, Zakharenko NF, Ivanova $T$, et al. Ulipristal acetate versus placebo for fibroid treatment before surgery. N Engl J Med 2012;366:409-20.

67. Donnez J, Tomaszewski J, Vázquez F, Bouchard P, Lemieszczuk $B$, Baró $F$, et al. Ulipristal acetate versus leuprolide acetate for uterine fibroids. N Engl J Med 2012;366:421-32.

68. Donnez J, Vázquez F, Tomaszewski J, Nouri K, Bouchard P, Fauser $B C$, et al. Long-term treatment of uterine fibroids with ulipristal acetate. Fertil Steril 2014;101:1565-1573. e1-18.

69. Donnez J, Hudecek R, Donnez O, Matule D, Arhendt $H J$, Zatik J, et al. Efficacy and safety of repeated use of ulipristal acetate in uterine fibroids. Fertil Steril 2015;103:519-527.e3.

70. Donnez J, Donnez O, Matule D, Ahrendt HJ, Hudecek R, Zatik J, et al. Long-term medical management of uterine fibroids with ulipristal acetate. Fertil Steril 2016;105:165173.e4.

71. Donnez J, Donnez O, Courtoy GE, Dolmans MM. The place of selective progesterone receptor modulators in myoma therapy. Minerva Ginecol 2016;68:313-20.

72. Mutter GL, Bergeron C, Deligdisch L, Ferenczy A, Glant $M$, Merino $M$, et al. The spectrum of endometrial pathology induced by progesterone receptor modulators. Mod Pathol 2008;21:591-8.

73. Williams AR, Bergeron C, Barlow DH, Ferenczy A. Endometrial morphology after treatment of uterine fibroids with the selective progesterone receptor modulator, ulipristal acetate. Int J Gynecol Pathol 2012;31:556-69.

74. Dutertre M, Smith CL. Molecular mechanisms of selective estrogen receptor modulator (SERM) action. J Pharmacol Exp Ther 2000;295:431-7.

75. Liu J, Matsuo H, Xu Q, Chen W, Wang J, Maruo T. 


\section{Obstetrics \& Gynecology Science}

Geum Seon Sohn, et al. Current medical treatment of uterine fibroids

Concentration-dependent effects of a selective estrogen receptor modulator raloxifene on proliferation and apoptosis in human uterine leiomyoma cells cultured in vitro. Hum Reprod 2007;22:1253-9.

76. Deng L, Wu T, Chen XY, Xie L, Yang J. Selective estrogen receptor modulators (SERMs) for uterine leiomyomas. Cochrane Database Syst Rev 2012;10:CD005287.

77. Lingxia X, Taixiang W, Xiaoyan C. Selective estrogen receptor modulators (SERMs) for uterine leiomyomas. Cochrane Database Syst Rev 2007:CD005287.

78. Wu T, Chen X, Xie L. Selective estrogen receptor modulators (SERMs) for uterine leiomyomas. Cochrane Database Syst Rev 2007:CD005287.

79. Palomba S, Orio F Jr, Morelli M, Russo T, Pellicano M, Zupi $\mathrm{E}$, et al. Raloxifene administration in premenopausal women with uterine leiomyomas: a pilot study. J Clin Endocrinol Metab 2002;87:3603-8.

80. Ishikawa H, Reierstad S, Demura M, Rademaker AW, Kasai $\mathrm{T}$, Inoue $\mathrm{M}$, et al. High aromatase expression in uterine leiomyoma tissues of African-American women. J Clin Endocrinol Metab 2009;94:1752-6.
81. Duhan N, Madaan S, Sen J. Role of the aromatase inhibitor letrozole in the management of uterine leiomyomas in premenopausal women. Eur J Obstet Gynecol Reprod Biol 2013;171:329-32.

82. Hilário SG, Bozzini N, Borsari R, Baracat EC. Action of aromatase inhibitor for treatment of uterine leiomyoma in perimenopausal patients. Fertil Steril 2009;91:240-3.

83. Brito LG, Candido-dos-Reis FJ, Magario FA, Sabino-deFreitas MM. Effect of the aromatase inhibitor anastrozole on uterine and leiomyoma Doppler blood flow in patients scheduled for hysterectomy: a pilot study. Ultrasound Obstet Gynecol 2012;40:119-20.

84. Parsanezhad ME, Azmoon M, Alborzi S, Rajaeefard A, Zarei A, Kazerooni T, et al. A randomized, controlled clinical trial comparing the effects of aromatase inhibitor (letrozole) and gonadotropin-releasing hormone agonist (triptorelin) on uterine leiomyoma volume and hormonal status. Fertil Steril 2010;93:192-8.

85. Song H, Lu D, Navaratnam K, Shi G. Aromatase inhibitors for uterine fibroids. Cochrane Database Syst Rev 2013:CD009505. 